\title{
Agent based Mobile Negotiation for Personalized Pricing of Last Minute Theatre Tickets
}

\author{
Kun Chang Lee \\ Professor at SKK Business School, WCU Professor at Department of Interaction Science, \\ Sungkyunkwan University, Seoul 110-745, Republic of Korea \\ Habin Lee* \\ Brunel Business School, Brunel University, Kingston Lane,Uxbridge, UB8 3PH, UK \\ Tel. +44 1895 267414, Email. Habin.Lee@brunel.ac.uk \\ Namho Lee \\ EMC Korea, Yeoksam 1-737, Kangnam-Ku, Seoul 135-984, Republic of Korea
}

\footnotetext{
* All correspondence to

Dr Habin Lee

Brunel Business School

Brunel University

Kingston Lane, Uxbridge, Middlesex, UB8 3PH

UK

Tel. +44 1895267414

Email. Habin.Lee@brunel.ac.uk
} 


\title{
Agent based Mobile Negotiation for Personalized Pricing of Last Minute Theatre Tickets
}

\begin{abstract}
This paper proposes an agent based mobile negotiation framework for personalized pricing of last minutes theatre tickets whose values are dependent on the time remaining to the performance and the locations of potential customers. In particular, case based reasoning and fuzzy cognitive map techniques are adopted in the negotiation framework to identify the best initial offer zone and adopt multi criteria decision in the scoring function to evaluate offers. The proposed framework is tested via a computer simulation in which personalized pricing policy shows higher market performance than other policies therefore the validity of the proposed negotiation framework.
\end{abstract}

Key words: mobile negotiation, case based reasoning, fuzzy cognitive map, personalized pricing, mobile commerce.

\section{Introduction}

The pricing mechanism of theatre tickets has been one of the research issues due to its perishable nature. The value a perishable commodity deteriorates as time goes and therefore the negotiation of the price requires considering time left to the product or service (Chun 2003). Therefore discriminated pricing strategy that revises prices of a perishable product and service periodically as its expiration time comes close is widely implemented by theatres nowadays, and it is reported that such strategy brings better performance to the theatres (Huntington 1993).

On the other hand, the values of last minute tickets are perceived differently by potential customers according to the distances between their current locations and the theatre in which the performance is played as well as the time left and personal preferences on the genre of the performance. Discriminated pricing strategy still does not fully consider such individual contexts 
of the purchasing decision making of customers and is regarded as static. The difficulty of implementing personalized pricing that considers individual purchasing contexts comes from the managerial and administrative cost to update prices every hour or minute (Chun 2003). Therefore most of the pricing mechanisms in the literatures are based on probability distribution on potential demand of future market rather than current market demand.

This paper aims to propose an agent based mobile negotiation mechanism to enable real time personalized pricing of last minute theatre tickets whose values are dependent on the locations of potential purchasers as well as their preferences. It is vital for the service provider to identify potential customers who are able to and willing to purchase the ticket at an affordable price through a real time negotiation rather than to leave the seats uncharged. According to (Esteves 2009), personalized pricing or price discrimination can increase industry profit when the service providers can have preference information of consumers.

While there are many negotiation mechanisms proposed for electronic commerce (see Lomuscio (2003) for example), a negotiation technique that can be used for mobile commerce where customers' locations play a key role in negotiations is yet to be found. Supporting mobile negotiation for last minute tickets requires considering following aspects. Firstly, determining the initial offer price by a seller agent is an issue because starting with an unrealistic price can make the negotiation process time consuming. Considering the negotiation is usually done few hours before the closure time of a performance, it is crucial to complete the negotiation as soon as possible before the seats become useless. Secondly, the decision whether to accept an offer from counter party is usually done by a single criteria (for example, accept an offer if the offered price is lower than maximum price). However, due to its dynamism, the decision on whether to accept a price offer is usually require considering multiple dimensions. Also some variables of 
dimensions change during the negotiation phases (for example, the location of the customers and the number of available seats) and it is necessary to make decision considering the changes on the situation. Therefore the integration of a multi-dimensional decision making mechanism in the negotiation mechanism is required.

Multi-agent based negotiation framework proposed in this paper adopts case based reasoning (CBR) and fuzzy cognitive map (FCM) to determine agreed prices of a last minute ticket between mobile consumers and service provider considering the user preferences and current location. The proposed framework is tested by comparing with other pricing mechanisms to show its advantages in a simulated environment.

The organization of the paper is as follows. Next section provides background information of the selected technologies in the paper. The proposed negotiation framework is detailed in section 3 which is followed by an experiment section that provides the details of the experiment used to verify the personalized pricing concept. Then the contributions of the paper are summarized in discussions section in which the novelty of the paper is compared with existing studies. Finally, the conclusion section summarized the paper and identifies the future research agenda in this area.

\section{Background}

\subsection{Multi-agent systems}

This paper adopts multi-agent system (MAS) as a basic computing paradigm to semi-automate the negotiation processes between sellers and buyers. MASs solve a domain problem via the 
cooperation of intelligent and autonomous agents that are distributed over a network (Ferber 1999).

Multi-agent systems have offered a new dimension for coordination in an enterprise (Lee et al 2007). The multi-agent system provides an effective platform for coordination and cooperation among disputing multiple entities in real world cases. For example, when a conflict occurs between buyers and sellers over limited resource, it is difficult for a single authority or committee to reconcile it to the full satisfaction of all the entities concerned. The autonomy of an agent is a desirable to represent the self-interested nature of negotiating entities. That is, the delegation of a task to an agent is done via asynchronous message exchange rather than method invocation. The former allow an agent can decide whether it would like to take the task while the latter mandates the execution of the task. In negotiation context, the autonomy of an agent can best be used to model the decision making to maximize its self-interest.

Intelligence of an agent is another desirable feature that allows the agent can make decision considering multiple factors to maximize its utility. Finally, sociality of an agent allow it identify right agents to interact via asynchronous messages which contains messages expressed via an agent communication language (ACL, see Ferber (1999) for more details on ACL).

As all communications among agents are done via asynchronous message exchanges, it is vital to manage the maintenance of conversation states of an agent when it is involved with conversations with multiple agents at a time. For this purpose, a conversation thread that manages the progress of a conversation with one or more counter-part agents is used by an agent. Each conversation thread takes a message from the message queue of the agent by referring its unique conversation thread identifier. Each conversation thread also employs a conversation 
policy (Greaves et al 2000) that defines the sequence of messages to be exchanged among participating agents for a conversation. A conversation policy (sometimes called as interaction protocol) allows two or more agents can exchange messages in a right order.

In MAMON, sellers and buyers are modeled as agents that represent their interests. Seller agents make decision to maximize the profits of ticket sellers and buyer agents the utilities of buyers. The exchange of information about initial offer by sellers and counter-offers by buyers are done via asynchronous messages according to predefined conversation policy.

\subsection{Case based reasoning}

Terms related to CBR include exemplar-based reasoning, instance-based reasoning, memorybased reasoning, case-based reasoning, and analogy-based reasoning. The basic idea of CBR is to solve new problems by adopting the solutions used to solve similar problems (Hansen and Meservy 1994). It is based on the assumption that if two problems are similar, then the solutions are probably also similar with each other. Therefore how to measure the similarity is important in CBR systems. In a CBR based problem solving, old problems and their solutions are stored in a database of cases - the case base. Often the cases are stored as collections of attribute-value pairs, but for complex tasks it is necessary to explicitly represent the hierarchical structure of the cases by describing them as structured objects, using inheritance, object decomposition, and possibly other relations between the object parts. When a new problem needs to be solved, a CBR system searches for old problems that are most similar to the new problem. The solutions to the old problem can be adapted to meet the requirements of the new problem to resolve any differences between the two. CBR has successfully been applied to different problem domains including 
bankruptcy prediction (Cho et al 2010; Park and Han 2002), business failure prediction (Li and Sun 2011), and fault diagnosis (Yang et al 2004) among others in the last decade.

Considering the advantages of CBR above, MAMON adopts it to reduce time to identify initial offer zone by ticket seller agents in a negotiation with buyer agents. CBR is especially useful for m-commerce users who do not have sufficient access to all information to consider all the constraints before making a purchase decision. By retrieving appropriate past examples and suggesting them as benchmarking points, CBR can help theatres make fast decisions on the initial price offer zones.

\subsection{Fuzzy Cognitive Map}

Cognitive map was initially proposed (Axelrod 1976) to represents social knowledge via causal relationships among major concepts. In a cognitive map, a concept is represented as a node and causal relationship between two nodes an arrow. A cognitive map allows analysts analyse the complex relationships among target domain via a simple. However, despite its wide application, cognitive map had a limitation in representing uncertainty involved in the causal relationships among concepts in a map. Kosko (1986) extended the cognitive map to allow modelers add uncertainty on the causal relationships among concepts and named it as fuzzy cognitive map (FCM) in late 1980's.

An FCM allows modelers analyze the strength of impacts of a concept node to other concept nodes. In an FCM, arrows are attached with a signed weight value between 0 and 1 . The bigger the value is, the stronger impact is assumed between two concepts. Arrow also indicates the direction of such impact. Fuzzy causal algebra is applied to calculate the amount of indirect and maximum impacts from a concept node to another. 
Due to the analytic power of FCM, it has been applied to solving unstructured problems in wide domains. Examples, although not exhaustive, drought and desertification analysis (Maraglino et al 2010), strategic planning problems (Ramaprasad and Poon 1985), group cognitive mapping (Tegarden and Sheetz 2003), designing EDI (electronic data interchange) control (Lee and Han 2000) and risk analysis and management (Lazzerini and Mkrtchyan 2011).

By integrating FCM, MAMON agents are able to provide decision makers on the move with more improved decision support functions. There are many factors that are influencing mcommerce decisions either indirectly or directly. However, users cannot afford to consider all the causal relationships among those factors thoroughly in a situation when they need to move and there is not enough time. In that situation, FCM can provide an analytical and systematical way of investigating causal relationships between all the factors related to the m-commerce situation.

\section{MAMON: Multi-Agent based MObile Negotiation framework}

MAMON is a location based negotiation framework where buyer agents represent buyers on the move and a seller agent a seller under time and location constraints. Three types of agent play a major role in MAMON: B-agent, S-agent, and M-agent. B-agents are usually located on buyers' mobile devices to represent the buyers' interests while S-agents on more powerful desktops or servers to represent sellers. Finally, an M-agent is usually located on a desktop or server and acts as a mediator between S-agents and B-agents. The two types of agent subscribe to an M-agent which store information needed in negotiation processes, such as the location of S-agents and Bagents and related ticket information. An M-agent only mediates the two agents as a registration of agents but is not involved in the negotiation processes of the two types of agents. 


\subsection{S-agent}

Fig. 1 shows a flow chart that represents the internal logic of an S-agent for a negotiation to sell a last minute ticket. The ultimate goal of an S-agent is to maximize the profit of a seller it represents. For this purpose, an S-agent seeks potential buyers in within a specific time limit. Then it calculates the bid price of the selling ticket based on CBR, and sends an offer including price and ticket details to the potential B-agents.

A wide variety of past selling instances are stored in a case base, and the proposed CBR uses the similarity index (SI) to select a case that has the highest similarity with current selling situation. Once such cases are identified, the price offer can be made referring to the price information attached to the selected cases.

In this paper, a priority adjusted case selection (PACS) mechanism is proposed to have an enhanced initial bid mechanism based on CBR. PACS select a case (c) from a case base using equation (1). 


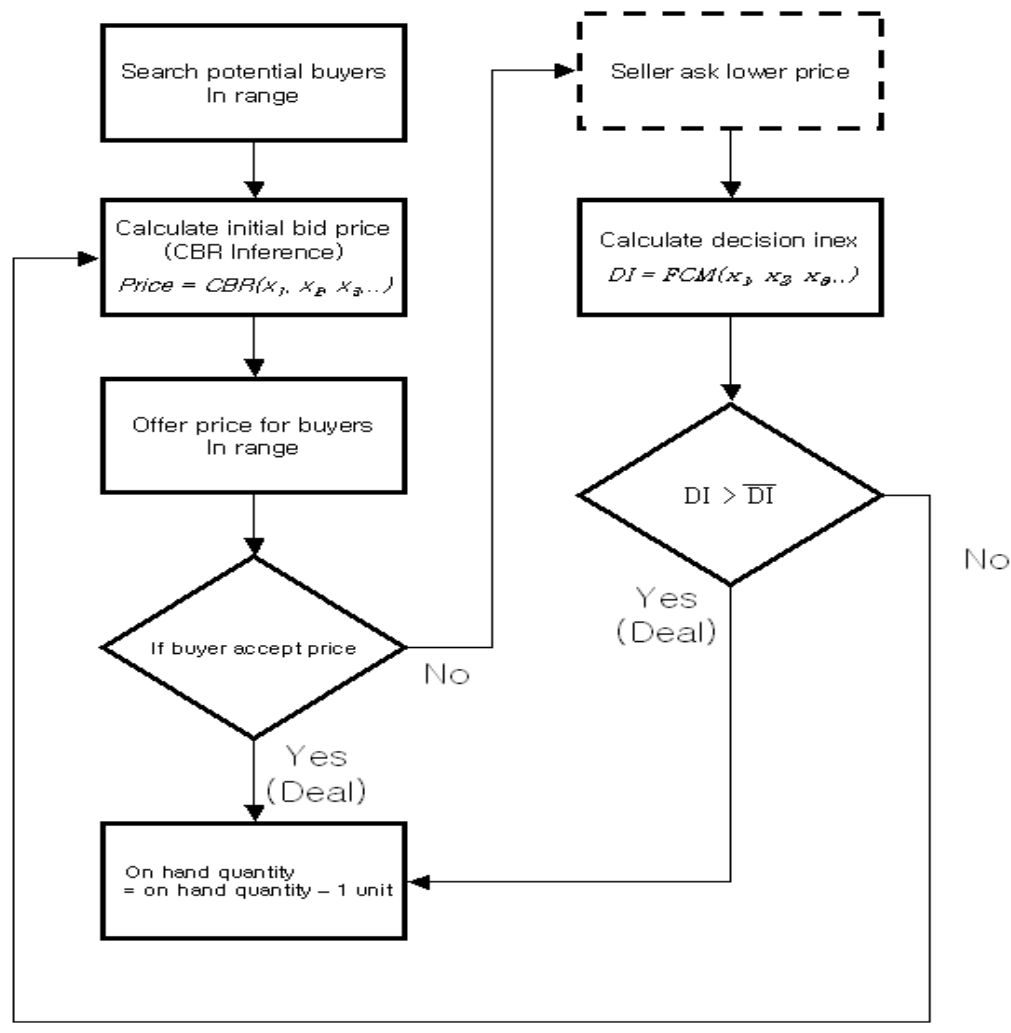

Fig. 1 Negotiation process of S-agent

$$
c=\min S I_{i}\left(c_{\text {new }}\right)(t) \Phi_{j}\left(\min \operatorname{DIFF}\left(c_{i, j}, c_{n e w, j}\right)\right)
$$

In equation (1), the operator $(t)$ first returns a value from the evaluation of left hand side operand function $\left(\min S I_{i}\left(c_{\text {new }}\right)\right)$. $\min S I_{i}\left(c_{\text {new }}\right)$ returns a case whose $S I$ value is smaller or at least equal than other cases $(\mathrm{i}=1,2, \ldots, \mathrm{m})$. The SI value of each case in comparison with new case $\left(c_{\text {new }}\right)$ is calculated using equation (2).

$$
S I_{i}=\sqrt{\sum_{\mathrm{j}=1}^{\mathrm{n}}\left(N_{j}-S_{i j}\right)^{2}}
$$


In equation (2), $N_{j}$ indicates $j^{\text {th }}(j=1,2, \ldots, \mathrm{n})$ attribute value of a new case, and $S_{i j}$ denotes $j^{\text {th }}$ attribute value of $i^{\text {th }}(i=1,2, \ldots, \mathrm{m})$ case in the case base.

If the function returns more than one value, then the operator evaluates the operand function on the right hand side $\left(\Phi_{j}\left(\min \operatorname{DIFF}\left(c_{i, j}, c_{n e w, j}\right)\right)\right)$. The DIFF function is defined in equation (3).

$$
\operatorname{DIFF}\left(\mathrm{N}_{\mathrm{j}}, \mathrm{S}_{\mathrm{ij}}\right)=\left|\mathrm{N}_{\mathrm{j}}-\mathrm{S}_{\mathrm{ij}}\right|
$$

That is, DIFF function returns the absolute value of the difference between two argument values $\left(\mathrm{N}_{\mathrm{j}}, \mathrm{S}_{\mathrm{ij}}\right)$. The $\Phi_{p j}$ functions go through for each attribute $(\mathrm{j}=1,2, \ldots, \mathrm{n})$ from highest priority attribute to lower one until a tie is broken among the comparison cases when DIFF function is applied to the attribute values.

As shown above, PACS uses Euclidean distances between a new case and existing cases in a Case Base to identify the most similar case. The initial price of the new case for the negotiation process is simply the price of the identified the most similar case in the case base. If there are ties on the Euclidean distances between two or more cases in the Case Base, then the tied cases are compared on the attribute with highest priority. The comparison is repeated on the lower priority attributes until the tie is broken. A randomly selected case is chosen if the tie is not resolved after the comparisons on the all attributes. 


\begin{tabular}{|l|l|l|l|l|l|l|l|}
\hline & Case ${ }_{\text {new }}$ & Case 1 & Case 2 & Case 3 & $\ldots$ & Case m & Priority \\
\hline Attribute 1 & $\mathrm{N}_{1}$ & $\mathrm{~S}_{11}$ & $\mathrm{~S}_{21}$ & $\mathrm{~S}_{31}$ & $\ldots$ & $\mathrm{S}_{\mathrm{m} 1}$ & $\mathrm{P}_{3}$ \\
\hline Attribute 2 & $\mathrm{N}_{2}$ & $\mathrm{~S}_{12}$ & $\mathrm{~S}_{22}$ & $\mathrm{~S}_{32}$ & $\ldots$ & $\mathrm{S}_{\mathrm{m} 2}$ & $\mathrm{P}_{2}$ \\
\hline Attribute 3 & $\mathrm{N}_{3}$ & $\mathrm{~S}_{13}$ & $\mathrm{~S}_{23}$ & $\mathrm{~S}_{33}$ & $\ldots$ & $\mathrm{S}_{\mathrm{m} 3}$ & $\mathrm{P}_{1}$ \\
\hline$\ldots$ & $\ldots$ & $\ldots$ & $\ldots$ & $\ldots$ & $\ldots$ & $\ldots$ & $\ldots$ \\
\hline Attribute n & $\mathrm{N}_{\mathrm{n}}$ & $\mathrm{S}_{1 \mathrm{n}}$ & $\mathrm{S}_{2 \mathrm{n}}$ & $\mathrm{S}_{3 \mathrm{n}}$ & $\ldots$ & $\mathrm{S}_{\mathrm{mn}}$ & $\mathrm{P}_{\mathrm{n}}$ \\
\hline $\mathrm{SI}_{i}$ & & $\mathrm{SI}_{1}$ & $\mathrm{SI}_{2}$ & $\mathrm{SI}_{3}$ & $\ldots$ & $\mathrm{SI}_{\mathrm{m}}$ & $1^{\text {st }}$ compare \\
\hline $\mathrm{SI}_{i, 3}$ & & $\left|\mathrm{~N}_{3}-\mathrm{S}_{13}\right|$ & $\left|\mathrm{N}_{3}-\mathrm{S}_{23}\right|$ & $\left|\mathrm{N}_{3}-\mathrm{S}_{33}\right|$ & $\ldots$ & $\left|\mathrm{N}_{3}-\mathrm{S}_{\mathrm{m} 3}\right|$ & $2^{\text {nd }}$ compare \\
\hline $\mathrm{SI}_{i, 2}$ & & $\left|\mathrm{~N}_{2}-\mathrm{S}_{12}\right|$ & $\left|\mathrm{N}_{2}-\mathrm{S}_{22}\right|$ & $\left|\mathrm{N}_{2}-\mathrm{S}_{32}\right|$ & $\ldots$ & $\left|\mathrm{N}_{2}-\mathrm{S}_{\mathrm{m} 2}\right|$ & $3^{\text {rd }}$ compare \\
\hline $\mathrm{SI}_{i, 1}$ & & $\left|\mathrm{~N}_{1}-\mathrm{S}_{11}\right|$ & $\left|\mathrm{N}_{1}-\mathrm{S}_{21}\right|$ & $\left|\mathrm{N}_{1}-\mathrm{S}_{31}\right|$ & $\ldots$ & $\left|\mathrm{N}_{1}-\mathrm{S}_{\mathrm{m} 1}\right|$ & $4^{\text {th }}$ compare \\
\hline$\ldots$ & & $\ldots$ & $\ldots$ & $\ldots$ & $\ldots$ & $\ldots$ & $\ldots$ \\
\hline $\mathrm{SI}_{i, \mathrm{n}}$ & & $\left|\mathrm{N}_{\mathrm{n}}-\mathrm{S}_{1 \mathrm{n}}\right|$ & $\left|\mathrm{N}_{\mathrm{n}}-\mathrm{S}_{2 \mathrm{n}}\right|$ & $\left|\mathrm{N}_{\mathrm{n}}-\mathrm{S}_{3 \mathrm{n}}\right|$ & $\ldots$ & $\left|\mathrm{N}_{\mathrm{n}}-\mathrm{S}_{\mathrm{mn}}\right|$ & n+1 $^{\text {th }}$ compare \\
\hline
\end{tabular}

Table 1 Priority adjusted Case selection method

Table 1 illustrates the process described above. The attributes of the case base are composed of the factors which the seller considers as important for the initial asking price and can be various according to the characteristics of the target ticket.

If a buyer accepts the price offered by the S-agent, then the negotiation process is completed. However, if no buyer accepts the price offered by the S-agent, and counter-offers with updated price are sent to the S-agent by B-agents, then the S-agent evaluates the counter-offers using FCM inference. 
FCM allows decision makers merge quantitative attributes with qualitative ones for their decision making. Usually, the identification of such attributes is performed by multiple experts who have experiences in the sales processes of last minute tickets. In this paper, the details of composing an FCM through the identification of attributes are skipped to make the paper concise. Nelson et al (2000) provide a detailed explanation on the process. Fig. 2 shows an example FCM for the negotiation in MAMON.

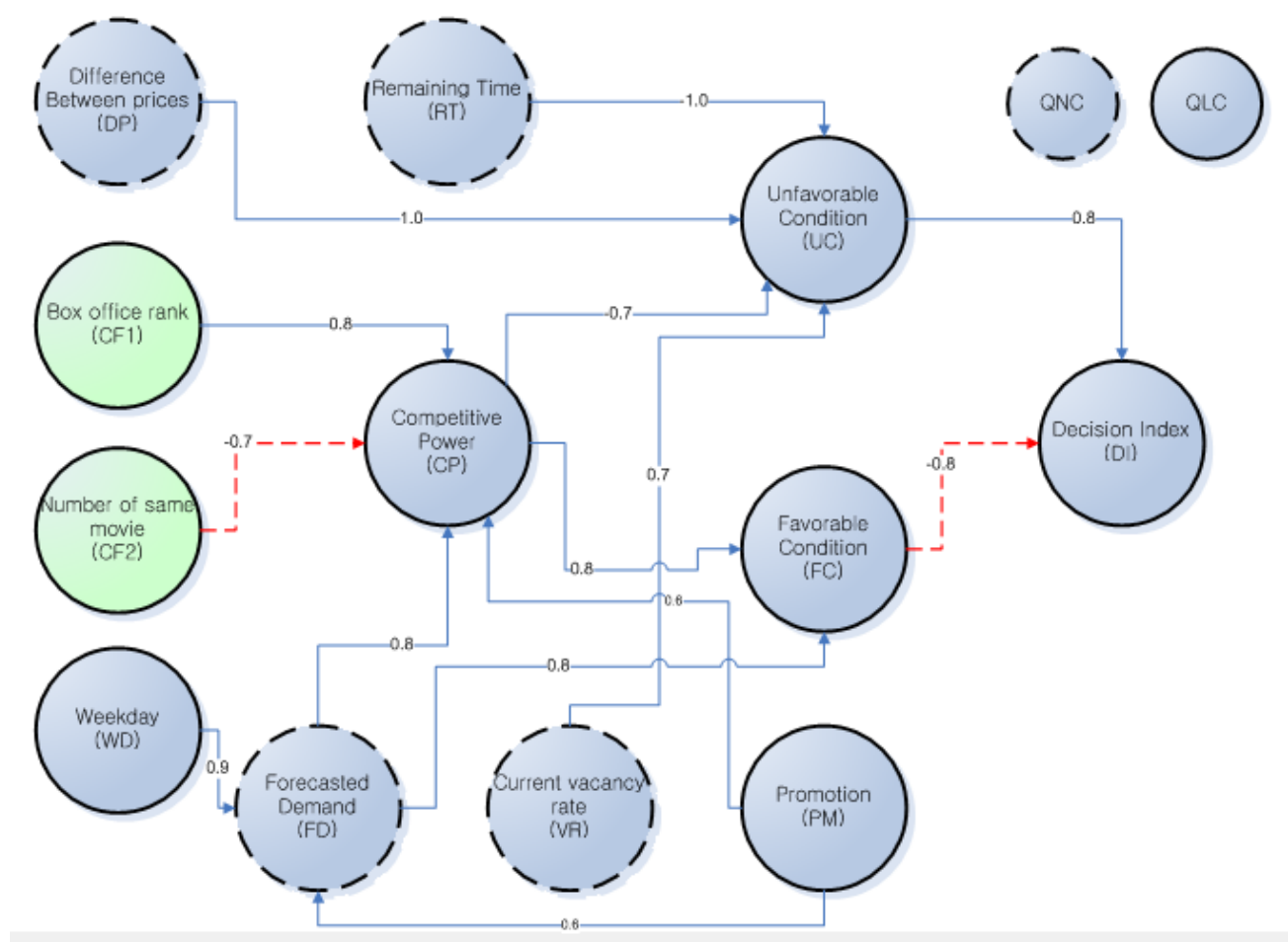

Fig. 2 A sample FCM for Decision index 
The FCM shows interactions among twelve factors. Solid circles represent quantitative variables while dotted circles qualitative ones. A decision variable, Decision Index, is determined by two qualitative variables: favorable condition and unfavorable condition. Favorable condition is determined by two other variables while unfavorable condition by four other variables. If a Bagent counter-offers an updated price, then the S-agent performs a forward-evolved inference to calculate the value of DI (Decision Index). The S-agent makes a deal with the B-agent if and only if the offered DI is bigger than the threshold value of DI otherwise move to next round of negotiation to agree on the price.

A forward-evolved inference process of an FCM is usually considered as a what-if analysis to gauge the impacts of a state event to one or more decision variables (Decision Index, DI in Fig. 2). The state event is usually represented as a concept vector that contains values of each concept in the FCM and represents current sale situation in real world.

The initial state vector is multiplied by the adjacency matrix of the FCM and new states of the system are derived through a transfer function. That is,

$$
C^{t+1}=f\left(C^{t} \times E\right)
$$

In equation (4), $C^{t+1}$ is a system state vector at time $\mathrm{t}+1, C^{t}$ a system state vector at time $\mathrm{t}, \mathrm{E}$ adjacent matrix of the FCM, and $f$ a transfer function. The transfer function $f$ is required to make the resulting concept values of the new state vector lies between -1 and 1 . The most widely used discrete transfer functions include sign function, threshold function, and trivalent function (Tsadiras 2008). The first two functions convert a resulting concept value into either 0 or 1 , the third into $[-1,0,1]$ while the sigmoid function any value between -1 and 1 . 
The state derivation through above formula is repeated until either the state of the system arrives at equilibrium where the same state is derived at certain point or falls into a limit cycle behavior, that is, a certain sequence of states are repeated.

The adjacency matrix $\underline{\boldsymbol{E}}$ corresponding to Fig. 2 is as follows.

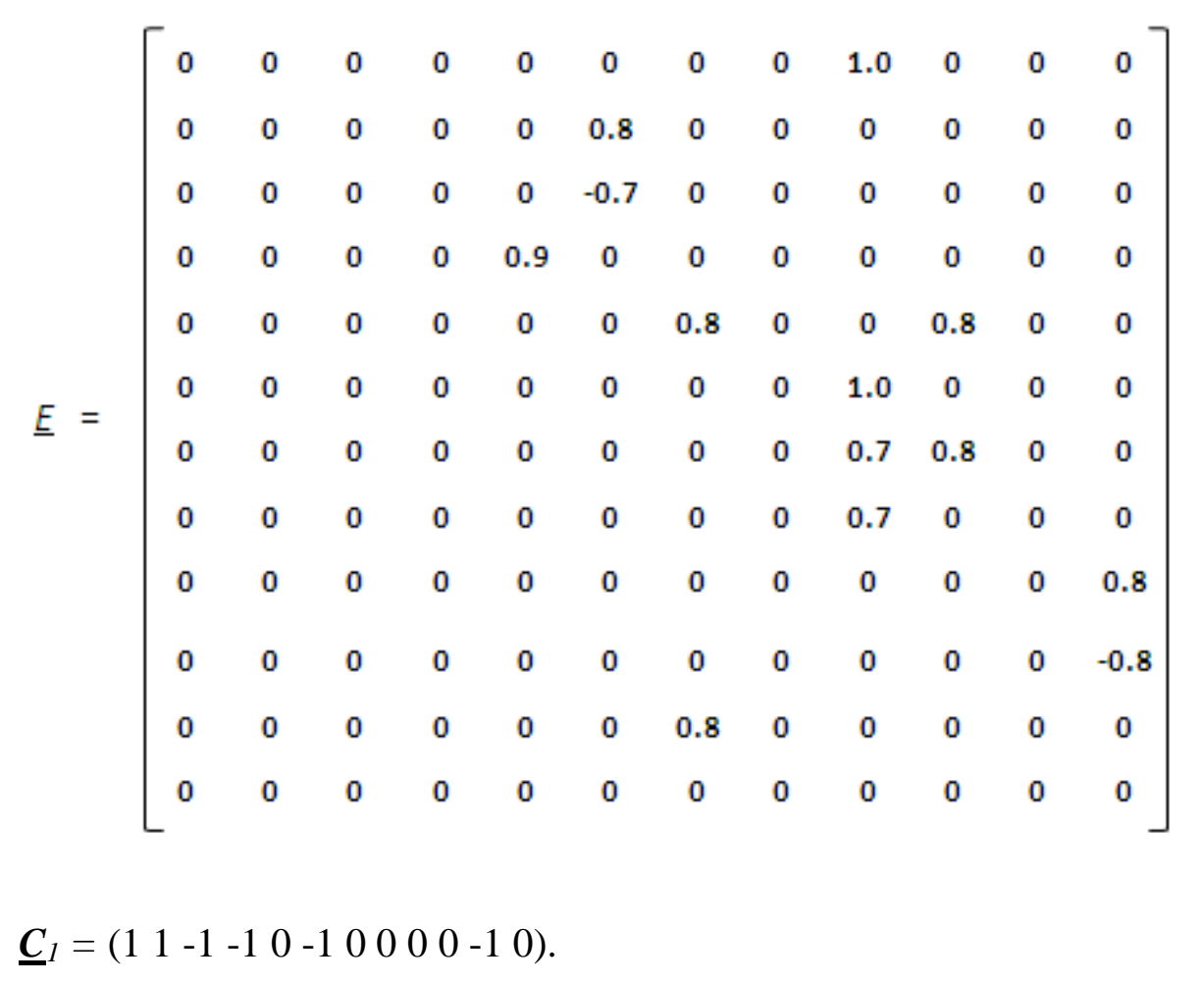

Let's assume that a seller's initial price bid has been rejected by buyers, and the seller has counter-offers from buyers for a ticket. It is also assumed that the price difference between buyers and the seller are small; the box office rank of the ticket is relatively high; the number of theatres that play the performance is relatively high; it is a weekday; remaining time to the performance is very short; and the theatre is implementing an aggressive promotion strategy. This negotiation context can be converted into the value between -1 and 1 and can be described by a vector as follows : 


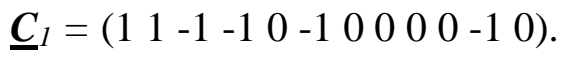

Multiplying this by $\underline{\boldsymbol{E}}$, we get the second concept node vector $\underline{\boldsymbol{C}}_{2}$.

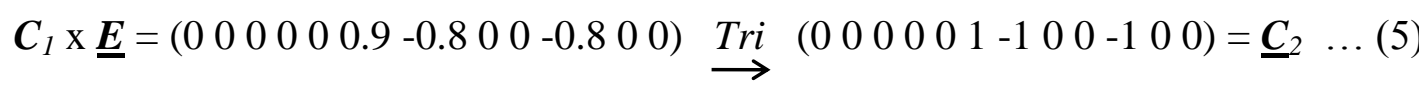

The $\underset{\text { Tri }}{\longrightarrow}$ in equation (5) is a trivalent function which converts a left-hand side Cartesian value into either -1 (if $<0$ ), 0 (if 0 ) or 1 (if $>0$ ). This process is repeated using the newly derived state vector until the system reaches to an equilibrium or limited cyclic behavior. If the inference process reaches to a equilibrium state, then the concept value of the decision variable (Decision Index) will determine whether a counter-offer price from a buyer can be accepted (DI $=0$ ) or rejected $(\mathrm{DI}=1)$.

\subsection{B-agent}

The role of B-agent is relatively simple compared to that of an S-agent due to two reasons. Firstly, B-agents usually are located on handheld devices which have limited computing power therefore not appropriate to adopt a sophisticated computing algorithm which may degrade the performance of the system in terms of computing time. Secondly, the final decision is usually made by human users rather than B-agents which are mostly responsible on recommending options available for the human users.

A B-agent incorporates following utility function:

$$
\mathbf{U}=\Sigma \mathbf{W}_{k} * \mathbf{F}_{k}, \quad \Sigma \mathbf{W}_{k}=1
$$

That is, a buyer's utility $\mathbf{U}$ is a summation of products between the buyer's preference weight on factor $\mathrm{k}\left(\mathbf{W}_{k}\right)$ and the buyer's preference value on factor $\mathrm{k}\left(\mathbf{F}_{k}\right)$. The sum of preference weights on all factors is 1 . 
The utility factors can include not only price, product, and quality but also contextual information such as the buyer's current location and environmental constraints. In this paper the weight values on utility factors were obtained via asking the buyer through a 7-scale questionnaire on mobile devices when B-agents are installed on their devices.

That is,

$$
W_{k}=S_{k} / \Sigma S_{k}
$$

In equation (6), $S_{k}$ is a 7 -scale score on the factor $\mathrm{k}$, and $\mathrm{k}=1,2, \ldots, h$. At the same time, the target levels of utility factors are also asked through the questionnaire. A target utility (TU) represents the maximum level the buyer is willing to pay for cost related variables (or minimum level the buyer wish to achieve for incentive related variables). If a B-agent gets a price offer from an S-agent and the offer does not meet the buyer's TU, then the B-agent calculates a counter-offer price as below. In MAMON, the price adjustment is made based on target utility, perceived utility from a ticket, and prior price offered as below.

$$
\begin{aligned}
& \boldsymbol{T U}=\boldsymbol{\Sigma} \boldsymbol{W}_{\boldsymbol{k}} * \boldsymbol{F}_{\mathrm{k}}^{*} \text {, where } F_{k}^{*} \text { is the goal target on factor } i \\
& \boldsymbol{P} \boldsymbol{U}_{l}=\Sigma \boldsymbol{W}_{\boldsymbol{k}} * \boldsymbol{F}_{\mathrm{kl}} \text {, where } F_{k l} \text { is the buyer's evaluation on ticket } l \text { for factor } k \\
& \text { price }_{l}^{t+1}=\text { price }_{l}^{t}-\left(\boldsymbol{T} \boldsymbol{U}-\boldsymbol{P} \boldsymbol{U}_{l}\right) / S_{f} \ldots \ldots \ldots \ldots \ldots \ldots \ldots \ldots \ldots \ldots \ldots \ldots \ldots \ldots \ldots \ldots
\end{aligned}
$$

In equation (7), the adjusted price of ticket $l$ is derived based on the previous offered price ( price $_{l}^{t}$ ), the target utility of a buyer (TU), and the perceived utility on the proposed ticket $l\left(P U_{l}\right)$. The speed factor $S_{\mathrm{f}}$ is used to reflect the degree of willingness of the buyer to have a successful negotiation. 
If the S-agent accepts the counter-offer, then the deal is completed. However, if rejected, then the B-agent can adjust the offer by decreasing its goal utility for next round of negotiation until the process is completed with an agreed deal or failure.

\section{Experiments}

The validity of the MAMON was tested through a computer simulation. The goal of the experiment was to test if the MAMON based mobile service market shows better performance (higher overall utility for buyers and profits for sellers) than traditional markets (without negotiations between sellers and buyers) do.

\subsection{Simulation model}

Theatres have 200 seats, cost $\$ 700$ per performance regardless of genres, and start selling tickets for vacant seats an hour before a performance commences. List price for a ticket is $\$ 7$, and a theatre plays four types of genre. The box office rankings of performances range between 1 and 10.

In the simulation, all customers are assumed that they do not have any other commitments apart from visiting theatres and will purchase a ticket only if the perceived utility of the ticket is equal or bigger than their target utilities. Customer's utility function includes following five factors: distance (D) from customer's current location to theater (for experiment, it is adjusted between 18 and 18); box office ranking of the movie (R); movie genre (G); newly adjusted ticket price that customers want $(\mathrm{P})$; and timeliness showing whether it is the exact time that customer wants (T). Based on the factors, ith customer's utility is calculated as follows.

$U_{i}=W_{D_{i}} \times D_{i}+W_{R_{i}} \times R_{i}+W_{G_{i}} \times G_{i}+W_{P_{i}} \times P_{i}+W_{T_{i}} \times T_{i}$ 
Table 2 addresses the various conditions and their converted values for the five utility factors.

\begin{tabular}{|l|l|l|}
\hline Utility factor & Condition & Converted value \\
\hline \multirow{4}{*}{$\begin{array}{l}\text { Distance from the } \\
\text { theater (D) }\end{array}$} & In 20 minutes & 50 \\
& In 40 minutes & 40 \\
& In 50 minutes & 30 \\
& More than 60 minutes & 20 \\
Box office ranking & 1,2 & 10 \\
$(\mathrm{R})$ & 3,4 & 50 \\
& 5,6 & 40 \\
\hline \multirow{2}{*}{ Movie genre (G) } & 7,8 & 30 \\
\hline \multirow{2}{*}{ Ticket price (P) } & 9,10 & 20 \\
\hline \multirow{2}{*}{ Timeliness (T) } & Customer wanted & 10 \\
\hline & For any new ticket price & 50 \\
\hline
\end{tabular}

Table 2 Buyer's utility factors

We classify theatres into three different groups according to their strategy for ticket pricing.

Firstly, normal transaction group sticks with fixed pricing strategy so no discount on the ticket price will be offered regardless of the time remaining to the performance. Secondly, passive transaction group adopts price discrimination strategy which discounts ticket prices periodically according to the time left to a performance. The customers in this group are equipped with mobile devices but no negotiation between customers and theatres. Theatres in this group offer discriminated prices to customers through mobile channels every 20 minutes depending on the vacancy rate- $\$ 6.5$ if vacancy rate $<40 \%, \$ 6.0$ if $40 \% \leq$ vacancy rate $\leq 50 \%, \$ 5.0$ if $50 \% \leq$ vacancy rate $\leq 60 \%, \$ 4.0$ if $60 \% \leq$ vacancy rate $\leq 70 \%, \$ 3.0$ if $70 \% \leq$ vacancy rate $\leq 80 \%, \$ 2.0$ if $80 \% \leq$ vacancy rate. Finally aggressive transaction group actors employ personalized pricing strategy via the MAMON negotiation mechanism for the transactions. Theaters in this group are 
offering different ranges of price using CBR inference where a case is composed of four input attributes (current vacancy rate $(\%)$, remaining time before the performance of the ticket (minutes), box office ranking of the performance, approximate number of reachable customers) and one output attribute (ticket price). Therefore, the price changes in accordance with the input attribute values which represent the circumstances of the theaters. The FCM as shown in Fig. 2 is used to inference the decision on accepting the newly adjusted price offered by the buyers. The theatre accepts the counter offer price if FCM result is less than 0 as unfavorable conditions is dominating in the market. Otherwise it rejects the counter offer and the buyer's seat number and show time are specified accordingly. Table 3 is used for the transformation of negotiation contexts into FCM concept values. 


\begin{tabular}{|c|c|c|}
\hline Constructs & Condition & Transformed values \\
\hline $\begin{array}{l}\text { Difference } \\
\text { between } \\
\text { prices(DP) }\end{array}$ & $\begin{array}{l}\text { Difference } \leq 10 \% \quad \text { seller's } \quad \text { price } \\
10 \%<\text { Difference } \leq 20 \% \\
20 \%<\text { Difference } \leq 30 \% \\
\text { Difference } \geq 30 \% \text { seller's price }\end{array}$ & $\begin{array}{l}-1 \\
-0.5 \\
0.5 \\
1\end{array}$ \\
\hline $\begin{array}{l}\text { Box office rank } \\
(\mathrm{CF} 1)\end{array}$ & $\begin{array}{l}\text { Rank 1,2 } \\
\text { Rank 3,4 } \\
\text { Rank 5,6 } \\
\text { Rank 7 } \sim 10\end{array}$ & $\begin{array}{l}1 \\
5 \\
-0.5 \\
-1\end{array}$ \\
\hline $\begin{array}{l}\text { Number of same } \\
\text { movie (CF2) }\end{array}$ & $\begin{array}{l}4 \sim \\
2 \sim 3 \\
1 \\
0\end{array}$ & $\begin{array}{l}1 \\
0.5 \\
-0.5 \\
-1\end{array}$ \\
\hline $\begin{array}{l}\text { Forecasted } \\
\text { Demand (FD) }\end{array}$ & $\begin{array}{l}\text { Many* } \\
\text { Normal** } \\
\text { Few*** }\end{array}$ & $\begin{array}{l}1 \\
0 \\
-1\end{array}$ \\
\hline $\begin{array}{l}\text { Remaining Time } \\
\text { (RT) }\end{array}$ & $\begin{array}{l}\text { Time } \leq 20 \text { minutes } \\
20 \text { minutes }<\text { Time } \leq 60 \text { minutes } \\
60 \text { minutes }<\text { Time } \leq 120 \text { minutes } \\
\text { Time } \geq 120 \text { minutes }\end{array}$ & $\begin{array}{l}1 \\
0.5 \\
-0.5 \\
-1\end{array}$ \\
\hline $\begin{array}{l}\text { Current vacancy } \\
\text { rate (SI) }\end{array}$ & $\begin{array}{l}40 \% \sim \\
30 \% \sim 40 \% \\
20 \% \sim 30 \% \\
10 \% \sim 20 \% \\
\sim 10 \%\end{array}$ & $\begin{array}{l}1 \\
0.7 \\
0.5 \\
-0.5 \\
-1\end{array}$ \\
\hline Promotion (PM) & $\begin{array}{l}\text { No promotion } \\
\text { Passive promotion } \\
\text { Aggressive promotion } \\
\text { Very aggressive promotion }\end{array}$ & $\begin{array}{l}-1 \\
-0.5 \\
0.5 \\
1\end{array}$ \\
\hline Weekday (WD) & $\begin{array}{l}\text { Weekend or holiday } \\
\text { Friday } \\
\text { Monday } \sim \text { Thursday }\end{array}$ & $\begin{array}{l}1 \\
0.7 \\
-1\end{array}$ \\
\hline $\begin{array}{ll}\text { Decision } & \text { Index } \\
\text { (DI) }\end{array}$ & $\begin{array}{l}\text { Reject offer } \\
\text { Accept offer }\end{array}$ & $\begin{array}{l}<0.5 \\
\geq 0.5\end{array}$ \\
\hline
\end{tabular}

*Many: \# of reachable customers is greater than the total \# of vacant seats of theaters

**Normal : \# of reachable customers is equal to the total \# of vacant seats of theaters

***Few: \# of reachable customers is less than the total \# of vacant seats of theaters

Table 3 Input constructs and conditions for theater's FCM 


\subsection{Results}

The MANON simulation prototype was developed using NetLogo. NetLogo is a programmable modeling environment for simulating natural and social phenomena. It is particularly well suited for modeling complex systems developing over time.

The initial conditions of the simulation are as follows. Total rounds of simulation is 30 , number of theaters 12 (4 in normal group, 4 in passive group, and 4 in aggressive group, number of customers 600 (evenly assigned to three groups), theaters in passive group sending discriminated prices every 20 minutes to nearby users, and theaters starting to offer discounted price 60 minutes before the show. The simulation results with MAMON are shown in Fig. 3 and the detailed results are provided in Appendix.

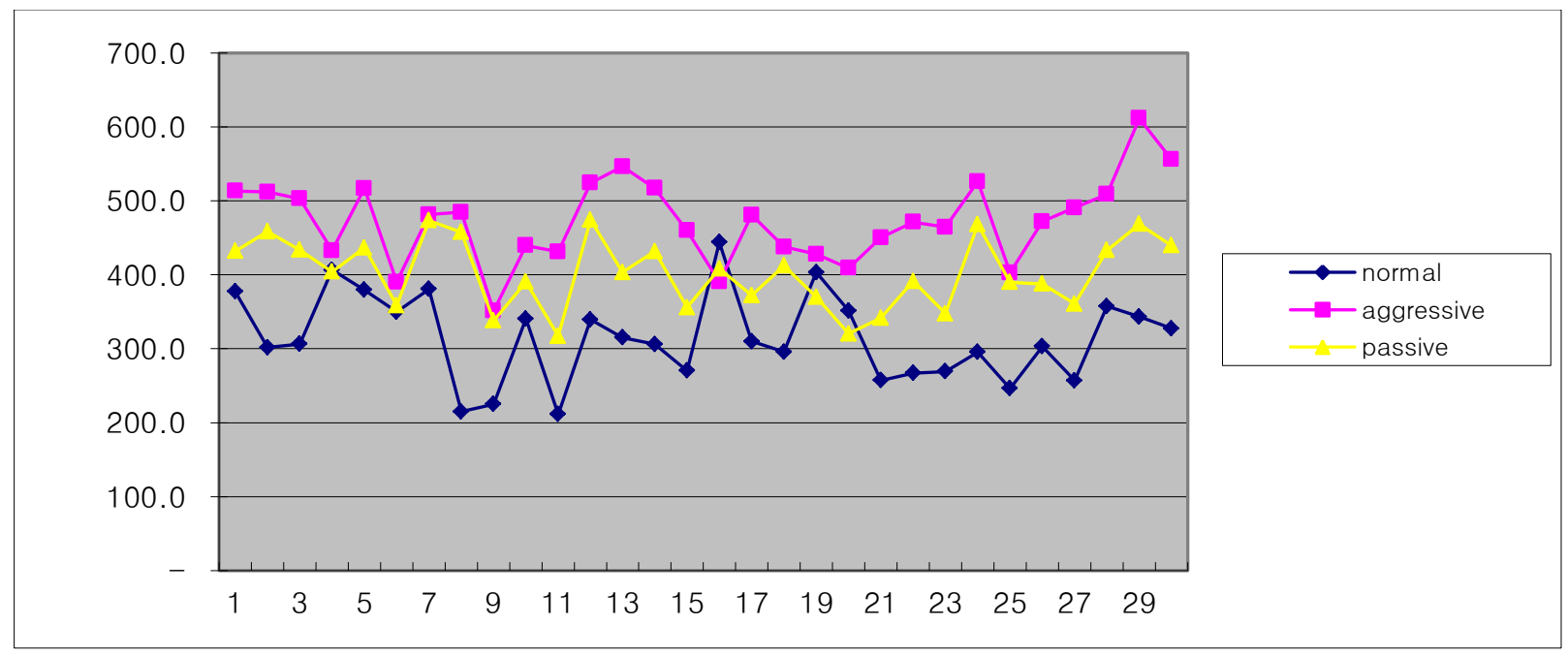

(a) Customers' average utilities 


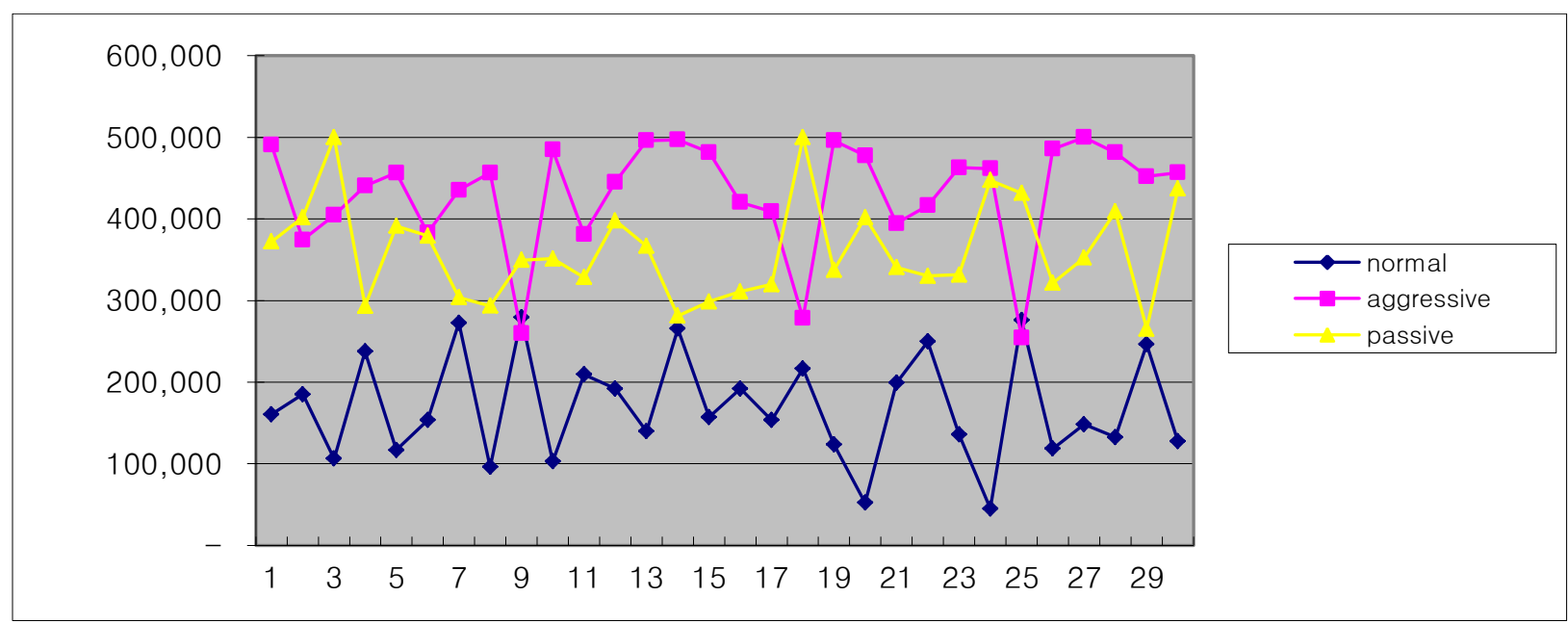

(b) Theaters' average profits

Fig. 3 Utilities and margins by MAMON simulation

Statistical results in Table 4 reveal that customers transacting with theatres in aggressive group achieved highest customer utilities and the theatres highest profits. The one way ANOVA and Pro Hoc tests results in Table 4 shows that the differences among the three groups are statistically significant $(\mathrm{p}<0.01)$ and there is no homogeneous subsets indicating the values of utilities and profits can be clearly categorized into three different groups respectively.

\begin{tabular}{|l|l|l|l|l|l|}
\hline & $\begin{array}{l}\text { Sum of } \\
\text { Squares }\end{array}$ & df & Mean Square & F & Sig. \\
\hline $\begin{array}{l}\text { Between } \\
\text { Groups }\end{array}$ & 377577.817 & 2 & 188788.908 & 63.857 & $\mathbf{. 0 0 0}$ \\
\hline $\begin{array}{l}\text { Within } \\
\text { Groups }\end{array}$ & 257208.903 & 87 & 2956.424 & & \\
\hline Total & 634786.720 & 89 & & & \\
\hline
\end{tabular}

(a) One way ANOVA results for the average customer utilities. 


\begin{tabular}{|l|l|l|l|l|}
\hline \multirow{2}{*}{ AUC } & \multirow{2}{*}{$\mathrm{N}$} & \multicolumn{3}{|l|}{ Subset for alpha $=.05$} \\
\cline { 3 - 5 } & & aggressive & passive & normal \\
\hline normal & 30 & 315.0833 & & \\
\hline passive & 30 & & 402.5667 & \\
\hline aggressive & 30 & & & 473.4500 \\
\hline Sig. & & 1.000 & 1.000 & 1.000 \\
\hline
\end{tabular}

(b) Post Hoc Tests results for the average customer utilities.

\begin{tabular}{|l|l|l|l|l|l|}
\hline & Sum of Squares & df & Mean Square & F & Sig. \\
\hline $\begin{array}{l}\text { Between } \\
\text { Groups }\end{array}$ & 1100084888039.023 & 2 & 550042444019.512 & 131.496 & $\mathbf{. 0 0 0}$ \\
\hline $\begin{array}{l}\text { Within } \\
\text { Groups }\end{array}$ & 363917603568.800 & 87 & 4182960960.561 & & \\
\hline Total & 1464002491607.823 & 89 & & & \\
\hline
\end{tabular}

(c) One way ANOVA results of Theatres average profits.

\begin{tabular}{|l|l|l|l|l|}
\hline \multirow{2}{*}{ AMC } & \multirow{2}{*}{$\mathrm{N}$} & \multicolumn{3}{|l|}{ Subset for alpha $=.05$} \\
\cline { 3 - 5 } & & aggressive & passive & normal \\
\hline normal & 30 & 169658.3333 & & \\
\hline passive & 30 & & 361521.6667 & \\
\hline aggressive & 30 & & & 431106.1333 \\
\hline Sig. & & 1.000 & 1.000 & 1.000 \\
\hline
\end{tabular}

(d) Post Hoc Tests of the Theatres average profits.

Table 4 Results of statistical test

\section{Discussions}

The contributions of the paper are twofold. Firstly, this paper tested the feasibility of personalized pricing in mobile commerce context. Perishable commodities pricing has been addressed in the literature since 1980s (Chun 2003; Jia and Hu 2011; Pasternack 1985). Jia and $\mathrm{Hu}$ (2011) are addressing the pricing and returning policies of perishable commodities like food. On the other hand, Chun (2003) is addressing the calculating the optimal fixed price for a given period. The major research issue in this area is finding reordering point of the inventory of 
decaying products and pricing policies. The common pricing policy is considering fixed time duration and do not consider the demand side preferences which was the core feature of the pricing mechanism of the paper. Pricing of tickets for performance is also addressed in the literature and the major focus on pricing of theatre tickets has been on the comparison between single price and price discrimination. Leslie (2004) argues that price discrimination improves the industry profits while it does not have impact to the consumer surplus. Esteves (2009) goes further on this argument by revealing the importance of considering consumer preference information on the price discrimination. On the other hand, Orbach and Einav (2007) analyzes the uniform pricing policy in film industry and argues that price discrimination would bring more profits to film exhibitors via change on legal constraints. In spite of such theoretical support on the benefits of price discrimination for the industry, the real world price discrimination mechanism is relatively limited. Leslie (2004) exemplifies the price discrimination in Broadway theatres as follows. Second-degree discrimination or non-linear discrimination set different prices for different seat qualities. Third-degree discrimination refers to mail coupon which is sent to potential consumers who are less willing to purchase the tickets. Finally, day-of-performance half-priced tickets which are sold in street ticket booth are further discrimination strategy. The personalized pricing via mobile negotiation addressed in this paper goes a step further by enabling the theatre managers set different prices for different potential consumers who have different preferences and therefore different value mechanisms.

Secondly, this paper also enhances the negotiation under time and location constraints through novel application of CBR and FCM in the negotiation strategy. Agent based negotiation has been widely adopted in electronic commerce domain since 1990s (Lomuscio et al 2003; Sandholm and Lesser 1995). The major issues in the discipline include identifying novel negotiation 
protocol and negotiation strategies. The former is mainly concerned with defining the message sequences that are exchanged between negotiating agents while the latter making the negotiating agents be able to decide an initial price, how to increase/decrease counter offer price, accept or reject an offer. Scoring functions are usually used to make decision on accepting or rejecting an offer from counter parties (Faratin et al 1998). While the initial offer or offer zone in a negotiation is reported to have significant effect on the negotiation outcome (Poucke and Buelens 2002), the literature lacks studies on mechanism to decide the initial offer. One of the most widely used scoring functions to evaluate an offer is based on weighted multi criteria function which produce a score (accept or reject) by summing weighted scores of multiple attributes (Faratin et al 1998; Huang et al 2010).

In this paper, the decision to accept/reject a counter-offer from a buyer agent by a seller agent is made via Fuzzy Cognitive Map which allows decision maker considers the causal relationships among multiple factors in the scoring function to accept or reject a counter-offer from a buyer agent. CBR inference incorporated within S-agents is the first approach in negotiation literature to identify initial offer zone under time constraints. Different price offer for different customers considering the current negotiation contexts is considered crucial in such time constraining circumstance. FCM finds its great potential in a negotiation process due to its generalized inference capability in a presence of a number of interrelated factors. Without FCM, decision makers would feel very stressful to consider all the complicated causal relationships among the relevant factors and expect future inference results. 


\section{Conclusion}

This paper proposed a mobile negotiation framework for personalized pricing of theatre tickets under time and location constraints. Its economic value and technical feasibility were tested by a simulation experiment. The personalized pricing strategy turned out to be more market effective than price discrimination and fixed pricing strategies. The feasibility of using CBR and FCM as a negotiation tools was also proved via the implementation of MAMON negotiation as a part of the simulation experiment.

This study poses some implications for future m-commerce research. M-commerce is blooming as mobile devices are providing increased convenience and performance in users' daily activities. However, there have been fewer efforts on developing mobile negotiation support systems in the literature and this study sheds a light on using the generalized multi-agents framework equipped with CBR and FCB for designing more enhanced mobile negotiation support systems. Furthermore, we proposed practical algorithms based on CBR and FCM to enhance the performance of the negotiations.

The future research directions are as follows. Firstly, the experiment was based on computer simulation and empirical testing of the proposed framework in real world context is required. Secondly, no comparison between the proposed negotiation algorithms (CBR for initial offer zone and FCM for effectiveness) with other negotiation mechanisms was made and will be included in the next research agenda. The comparison of the performance of negotiation algorithms is considered as a difficult task if not impossible. Firstly evaluation metrics need to be developed for the comparisons of negotiation performance. Additionally, the metrics need to 
include not only quantitative factors, but also qualitative factors. This will be incorporated in the future researches.

\section{Acknowledgment}

This research was supported by WCU(World Class University) program through the National Research Foundation of Korea funded by the Ministry of Education, Science and Technology (Grant No. R31-2008-000-10062-0).

\section{References}

Axelrod, R. (1976). Structure of Decision: The Cognitive Maps of Political Elites. Princeton: Princeton University Press, 1976.

Cho, S., Hong, H., \& Ha, B. C. (2010). A hybrid approach based on the combination of variable selection using decision trees and case-based reasoning using the Mahalanobis distance: For bankruptcy prediction. Expert Systems with Applications, 37 (4), 3482 - 3488.

Chun, Y.H. (2003). Optimal pricing and ordering policies for perishable commodities. European Journal of Operations Research, 144 (1), 68 - 82.

Esteves, R.B. (2009). Price discrimination with partial information: Does it pay off? Economics Letters, 105, $28-31$.

Faratin, P., Sierra, C., \& Jennings, N.R. (1998). Negotiation decision functions for autonomous agents. Robotics and Autonomous Systems, 24, 159 - 182. 
Ferber, J. (1999). Multi Agent System: An Introduction to Distributed Artificial Intelligence. Harlow: Addison Wesley Longman. Paper: ISBN 0-201-36048-9.

Greaves, M., Holmback, H., \& Bradshaw, J. (2000). What is a conversation policy? Issues in Agent Communication. Lecture Notes in Artificial Intelligence, 1916. Dignum, F. \& Bradshaw, $\mathrm{J}(\mathrm{ed}), 118-131$.

Hansen, J.V., Meservy, R.D., \& Wood, L.E. (1994). Indexing Tree and Pruning Concepts to Support Case-based Reasoning. Omega - International Journal of Management Science, 22 (4), $361-369$.

Huang, C.C., Liang, W.Y., Lai, Y.H., \& Lin, Y.C. (2010). The agent-based negotiation process for B2C e-commerce. Expert Systems with Applications, 37 (1), 348 - 359.

Huntington, P.A. (1993). Ticket pricing policy and box office revenue. Journal of Cultural Economics, 17 (1), $71-87$.

Jia, J. \& Hu, Q. (2011). Dynamic ordering and pricing for a perishable goods supply chain. Computers \& Industrial Engineering, 60 (2), $302-309$.

Kosko, B. (1986). Fuzzy cognitive maps. Journal of Man-Machine Studies, 24, 65 - 75.

Lazzerini, B. \& Mkrtchyan, L. (2011). Analyzing Risk Impact Factors Using Extended Fuzzy Cognitive Maps. IEEE Systems Journal, 5 (2), 288-297.

Lee, H., Mihailescu, P., \& Shepherdson, J. (2007). Realizing Team-Working in the Field: An Agent-based Approach. IEEE Pervasive Computing, 6 (2), 85-92.

Lee, S. \& Han, I. (2000). Fuzzy Cognitive Map for the Design of EDI controls. Information \& Management, 37 (1), 37-50. 
Leslie, P. (2004). Price discrimination in Broadway theatre. RAND J. Economics, 35 (3), 520 541.

Li, H. \& Sun, J. (2011). Principal component case-based reasoning ensemble for business failure prediction. Information \& Management, 48 (6), 220-227.

Lomuscio, A.R., Wooldridge, M., \& Jennings, N.R. (2003). A classification scheme for negotiation in electronic commerce. Group Decision and Negotiation, 12 (1), 31 - 56.

Maraglino, T., Ricco, V., Schiralli, M., Giordano, R., \& Pappagallo, G. (2010). The role of stakeholders' involvement to combat desertification: a case study in the Apulia region. In Proceedings of the $116^{\text {th }}$ EAAE Seminar "Spatial dynamics in agrifood systems: implications for sustainability and consumer welfare”, Parma, Italy, Oct $27-30^{\text {th }}, 2010$.

Nelson, K.M., Nadkarni, S., Narayanan, V.K., \& Ghods, M. (2000). Understanding software operations support expertise: A revealed causal mapping approach. MIS Quarterly, 24 (3), 475 $-507$.

Orbach, B.Y. \& Einav, L. (2007). Uniform prices for differentiated goods: The case of the movie-theater industry. International Review of Law and Economics, 27, 129 - 153.

Park, C.S. \& Han, I. (2002). A case-based reasoning with the feature weights derived by analytic hierarchy process for bankruptcy prediction. Expert Systems with Applications, 23 (3), 255 264.

Pasternack, B.A. (1985). Optimal pricing and return policy for perishable commodities. Marketing Science, 4 (2), 166 - 176. 
Poucke, D.V. \& Buelens, M. (2002). Predicting the outcome of a two-party price negotiation: Contribution of reservation price, aspiration price and opening offer. Journal of Economic Psychology, 23 (1), $67-76$.

Ramaprasad, A. \& Poon, E.A. (1985). A computerized interactive technique for mapping influence diagrams (MIND). Strategic Management Journal, 6 (4), 377 - 392.

Sandholm, T. \& Lesser, V. (1995). Issues in Automated Negotiation and Electronic Commerce: Extending the Contract Net Framework. In Proceedings of the First International Conference on Multiagent Systems, V. Lesser (eds), San Francisco, California, 1995, 328 - 335.

Tegarden, D.P. \& Sheetz, S.D. (2003). Group cognitive mapping: a methodology and system for capturing and evaluating managerial and organizational cognition. Omega - Inernational Journal of Management Science, 31, 2003, pp113 - 125.

Tsadiras, A.K. (2008). Comparing the inference using binary, trivalent and sigmoid fuzzy cognitive maps. Information Science, 178, 3880 - 3894.

Yang, B.S., Han, T.H., \& Kim, Y.S. (2004). Integration of ART-Kohonen neural network and case-based reasoning for intelligent fault diagnosis. Expert Systems with Applications, 26 (3), $387-395$. 
Appendix The simulation results

\begin{tabular}{|c|c|c|c|c|c|c|}
\hline \multirow{2}{*}{$\begin{array}{l}\text { Simulation } \\
\text { round }\end{array}$} & \multicolumn{3}{|c|}{ Average utility of customer } & \multicolumn{3}{|c|}{ Average margin of cinema } \\
\hline & normal & aggressive & passive & normal & aggressive & passive \\
\hline 1 & 377.4 & 513.2 & 431.9 & 160,500 & 490,561 & 372,050 \\
\hline 2 & 301.7 & 512.0 & 458.5 & 185,000 & 374,350 & 402,000 \\
\hline 3 & 306.3 & 502.9 & 433.7 & 106,250 & 404,561 & 499,975 \\
\hline 4 & 406.5 & 432.7 & 404.1 & 237,500 & 440,554 & 293,250 \\
\hline 5 & 379.7 & 516.9 & 436.6 & 116,750 & 456,481 & 391,300 \\
\hline 6 & 349.9 & 390.3 & 358.6 & 153,500 & 382,933 & 379,250 \\
\hline 7 & 380.7 & 481.4 & 473.4 & 272,500 & 435,343 & 303,725 \\
\hline 8 & 214.8 & 484.8 & 457.8 & 95,750 & 456,356 & 293,500 \\
\hline 9 & 224.9 & 351.1 & 338.1 & 279,500 & 259,523 & 349,500 \\
\hline 10 & 340.4 & 439.7 & 390.4 & 102,750 & 484,697 & 351,250 \\
\hline 11 & 211.4 & 431.1 & 317.0 & 209,500 & 381,274 & 328,500 \\
\hline 12 & 339.4 & 524.3 & 474.3 & 192,000 & 445,238 & 398,075 \\
\hline 13 & 315.2 & 546.3 & 403.4 & 139,500 & 496,005 & 366,825 \\
\hline 14 & 306.2 & 517.1 & 431.6 & 265,500 & 496,915 & 281,250 \\
\hline 15 & 270.3 & 459.7 & 355.9 & 157,000 & 481,426 & 298,675 \\
\hline 16 & 444.1 & 390.3 & 408.2 & 192,000 & 420,356 & 311,000 \\
\hline 17 & 310.0 & 480.7 & 372.2 & 153,500 & 409,113 & 319,750 \\
\hline 18 & 295.8 & 437.8 & 412.4 & 216,500 & 278,263 & 500,000 \\
\hline 19 & 403.2 & 427.8 & 370.1 & 123,750 & 496,030 & 337,200 \\
\hline 20 & 351.5 & 409.0 & 320.2 & 52,000 & 477,642 & 401,875 \\
\hline 21 & 257.3 & 450.4 & 341.7 & 199,000 & 394,516 & 340,700 \\
\hline 22 & 267.1 & 471.3 & 391.4 & 249,750 & 416,406 & 330,175 \\
\hline 23 & 269.3 & 464.5 & 347.5 & 136,000 & 462,857 & 331,600 \\
\hline 24 & 295.3 & 526.0 & 468.1 & 45,000 & 461,533 & 447,500 \\
\hline 25 & 246.2 & 402.8 & 390.1 & 276,000 & 254,445 & 431,675 \\
\hline 26 & 303.1 & 472.2 & 387.8 & 118,500 & 485,697 & 321,400 \\
\hline 27 & 256.9 & 490.7 & 360.7 & 148,250 & 499,977 & 352,575 \\
\hline 28 & 357.4 & 509.1 & 433.1 & 132,500 & 481,277 & 409,000 \\
\hline 29 & 343.2 & 611.5 & 468.6 & 246,250 & 452,114 & 265,125 \\
\hline 30 & 327.3 & 555.9 & 439.6 & 127,250 & 456,741 & 436,950 \\
\hline
\end{tabular}

